Quaestio facti. Revista Internacional sobre Razonamiento Probatorio Quaestio facti. International Journal on Evidential Legal Reasoning Seccion: Conjeturas y refutaciones N. 2 | 2021 pp. 313-324 Madrid, 2021 DOI: $10.33115 /$ udg_bib/qf.i2.22465 Marcial Pons Ediciones Jurídicas y Sociales (C) Nicola Muffato ISSN: 2604-6202

Recibido: 06/07/2020 | Aceptado: 01/12/2020 | Publicado: 28/01/2021 Editado bajo licencia Reconocimiento 4.0 Internacional de Creative Commons

\title{
STRONG, WEAK, OR APPARENT NATURALIZATION? RELATIVE PLAUSIBILITY THEORY AND CONCEPTUAL ANALYSIS
}

\author{
Nicola Muffato \\ Università degli Studi di Trieste \\ Associate Professor, Department of Legal Science, \\ Languages, Interpretation, and Translation
}

ABSTRACT: The paper questions the naturalized epistemological framework for Allen's relative plausibility theory (RPT). It is divided into two main sections: $\$ 1$ is devoted to show that the weak/ modest naturalism of Allen's central arguments make them hardly distinguishable from a traditional variety of conceptual analysis, which is neither a priori nor dependent on intuitions; $\$ 2$ deals with the "empirical" character of RPT, presenting some objections to its methodological assumptions and the ambitious project of providing a unifying account of the profoundly different facets of the process of proof in USA legal systems without relying on a sufficiently wide array of sociological and empirical data and without specifying the bridge principles governing the relations between the various domains of inquiry.

KEYWORDS: naturalized epistemology; conceptual analysis; relative plausibility theory; jurisprudence; methodology.

SUMMARY: 1. NATURALIZATION AND CONCEPTUAL ANALYSIS.- 2. THE EMPIRICAL CHARACTER OF THE RELATIVE PLAUSIBILITY THEORY.-3. REFERENCES

RECOMMENDED CITATION: MUFFATO, NICOLA, 2020: «Strong, Weak, Or Apparent Naturalization? Relative Plausibility Theory And Conceptual Analysis», in Quaestio facti, 2: 313-324. Madrid: Marcial Pons Ediciones Jurídicas y Sociales. DOI: http://dx.doi.org/10.33115/udg_bib/ qf.i2.22465 
In «Naturalized Epistemology and the Law of Evidence Revisited» ${ }^{1}$, Professor Ronald J. Allen presents a summary of several interesting and provocative arguments against the main competitors of the conception of legal evidence and proof he defends, relative plausibility theory (henceforth: RPT). Since I am quite sympathetic with almost all the objections he offers and with the general purpose of his criticism - to wit: one would better study how the rules on evidence of real legal systems are applied and followed, before trying to abstract from their conceptual articulation in order to rationalize them-I will not try to refute his refutations. I shall instead question the naturalized epistemological framework for RPT, taking cues from the quick brush strokes Allen gives in the target paper and the references to his related works, where this model is explored more in detail. In my view, not only does not the author carry until the end the naturalization project, but RPT does not even need such a support to overcome its a priori rivals. The paper is divided into two sections: $\$ 1$ is devoted to show the weak naturalism of RPT's epistemological framework; $\$ 2$ deals with the empirical evidence for RPT.

\section{NATURALIZATION AND CONCEPTUAL ANALYSIS}

1.1. In a path-breaking article written in 2001 with Brian Leiter, «Naturalized Epistemology and the Law of Evidence», Allen maintains that naturalized social epistemology provides a fruitful way of understanding evidence law. The authors endorse Alvin Goldman's attribution of a normative task to this kind of philosophical thought: the regulation of the social mechanisms and practices of belief-inculcation so that they could causally lead in a reliable way to knowledge ${ }^{2}$. From this point of view, epistemology is seen as a normative methodology of belief-acquisition, as a method of theory appraisal, and, eventually, as a proposal of partial reconceptualization of a practice: given certain conditions and contexts, it prescribes compliance with certain models and methods of belief-acquisition (e.g., of scientific inquiry) considered better than others because more reliable in yielding to true beliefs. In the case of evidence law, the task consists in evaluating a specific system of legal rules on evidence - thus seen also as a mechanism or practice of belief-inculcation - in the light of the accepted methodological prescriptions ${ }^{3}$ and a new conceptual apparatus ${ }^{4}$.

A naturalized (normative) epistemology, however, is also characterized by its continuity with and dependency upon empirical science $(s)^{5}$. Ascending to the level

Allen, 2020.

2 Cf. Allen \& Leiter, 2001: 1498: «Social epistemology, in the sense we adopt, is normative or regulative in its ambitions. We want to ask, as Goldman puts it in his recent important book on the subject, "Which [social] practices have a comparatively favorable impact on knowledge as contrasted with error and ignorance?"”.

3 Cf. Allen \& Leiter, 2001: 1501-1503.

4 Cf. Allen, i986.

5 Cf. Allen \& Leiter, 2001: 1497. 
of meta-epistemology, we can say that the methods for epistemological theorizing ought to be empirical/naturalistic, and scientific. As shown by Leiter ${ }^{6}$, this thesis is ambiguous. According to a first reading («Methods Continuity» thesis, henceforth MCT), it means that epistemological rules should reflect or imitate some relevant aspects/contents of scientific methods and choices. If so reconstructed, epistemology turns out to be an abstraction or a generalization from scientific methods ${ }^{7}$ : its norms and principles are gathered through a bottom-up process that moves from the rules scientists implicitly or explicitly follow when engaged in the thoughtful practice of theorizing ${ }^{8}$.

According to a second reading, epistemology has a distinctive method-e.g., conceptual explanation or conceptual analysis - which does not abstract from scientific methods, but must be constrained by the results of the theories developed following those methods ( Results Continuity» thesis, henceforth RCT): philosophical theses and conceptual claims must be supported or justified by the results of empirical theories. However, Leiter does not clarify what it means for empirical evidence (expressed by empirical propositions) to "support» or «justify» conceptual claims. Since he seems to rely on Goldman's view, I guess he assumes that epistemological theorizing does not start within science ${ }^{9}$, but must in any case have a factual basis of reliable cognitive processes on which epistemic concepts and properties supervene. For example, epistemic justification - a normative concept - supervenes on a social, reliable, causal mechanism of belief-inculcation, which can be studied empirically.

It must be noted, however, that in both readings epistemological rules only make sense if they can be accomplished with or applied by human beings - the rationalist "should" implies "can" principle»—and are seen as instrumental as to the achievement of epistemic goals. A naturalized approach to the evaluation of a system-rectius: a dynamic order - of legal rules of evidence consists in confronting the latter with a feasible methodology of belief-acquisition. Formal models (e.g., expected utility theory, probability theory, economic analysis) and other reductionist conceptions (e.g., sensitivity theory) of legal decision-making and fact-seeking fail this test because they commit the unforgivable sin of de-contextualization: their hypotheticals are too artificial and when applied in concrete contexts they generate pragmatic oddities or conceptual impossibilities. In brief, such models conflict with the facts about how we happen to reason and the limitations posed by real legal systems to the ascertainment of truth.

Allen and Leiter say they are doing normative epistemology. But then they add: "Whether epistemology in general should be naturalized is, in any case, irrelevant

6 Cf. Leiter, 1997: 289-290; 2017: \$1.

7 A problem I will not examine consists in the selection of the appropriate methods a naturalized jurisprudence should adopt.

8 Cf. Nixon, 2004.

9 This would explain Leiter's apparently incoherent claim that «the "concept" of law is not illuminated or fixed by empirical inquiry in the natural and social sciences» (LEITER, 1997: 302). 
to the question of whether naturalized epistemology provides a fruitful way of understanding evidence law. The latter is our contention" ${ }^{10}$. In the quoted passage, the authors seem to concede that even if the naturalization project in epistemology were wrong or unconvincing or useless from a meta-epistemological point of view, evidence law could in any case be usefully (correctly?) described (interpreted?) through the lens of naturalized epistemology. I'm not sure I've understood their point: given MCT or RCT, if naturalized epistemology cannot be defended, neither can a naturalized theory of evidence law. Maybe what they want to say is that the best way to explain evidence law consists in reconstructing it as at least partially informed by the empirical methods recommended by a naturalized normative epistemology. This explanation would not depend on the acceptance of the latter, even if Allen and Leiter do in fact accept it. In other words, the authors would be maintaining that evidence law is a mechanism of belief-inculcation, «a practice that has as one of its elements the production of knowledge»" ${ }^{11}$ and whose rules are, at the same time, legal, epistemic, and "naturalistic». This would be a strong contention, if its naturalism were demanding. Unfortunately, as we will see, this is not the case.

1.2. In a passage of the target paper, Allen retains the feasibility and instrumentality requirements, but offers a significantly different definition of «naturalized epistemology»: «As I am using the phrase, it refers to inquiries - analytical or empiricalinto how the human mind engages with its environment» ${ }^{12}$. The first thing to note here is that Allen has shifted from normative methodology to descriptive theorizing. I hesitate to qualify it as a piece of «descriptive methodology», because the phrase «inquiries into how the human mind engages with its environment» lends itself to two alternative interpretations: on one side, it could amount to a description or an explanation of the methods we follow in order to know and deal with our environment; on the other, it could be a description or an explanation of (i) some relevant features of our biology, or (ii) the capacities and abilities we display when immersed in our social and natural environment, or (iii) the functioning of a social epistemic practice. According to this second view-which, I suspect, is more in tune with Quine's replacement naturalism than with Goldman's version of RCT-epistemology does not describe «methods». Be as it may, such inquiries do not produce by themselves the regulation of social practices.

Second, the engraved disjunction- «analytical or empirical»—is a bit confounding, given that naturalization and rejection of the analytic/synthetic distinction are generally seen as coextensive. What do the two disjuncts mean, then? Let us start from "analytic». On a first interpretive hypothesis, Allen uses here the adjective as roughly synonymous with "conceptually regimented» but divorced from the allegedly a priori necessities accessible through the ordinary intuitions to which armchair

10 Cf. Allen \& Leiter, 2001: 1496-1497.

11 Cf. Allen \& Leiter, 2001: 1500.

12 Allen, 2020: 2. 
philosophy appeals. In fact, he ties his own conceptualizations «to either realistic hypotheticals or the actual state of affairs» ${ }^{13}$, trying to make them sensible to empirics, that is: to evidence gained through experience. In this case, the disjunction probably reveals the adoption of RCT.

On a second interpretation, quite typical in the literature concerned with the methodology of empirical research in social sciences, while «empirical», narrowly intended, is referred to methods and techniques of data collection, «analytic» is predicated of methods and techniques of description, modeling, and explanation of the data. It follows from this construction that legal analysis is part and parcel of empirical social sciences — such as, e.g., sociological jurisprudence or forensic psychologyand that Allen's epistemology is grounded on MCT rather than RCT.

Which interpretation is to be preferred? The explicit reference to Goldman's works suggests the first. However, as I anticipated, it is not clear how much Allen's method of epistemological theorizing-especially his RPT-is naturalistic. On one hand, some of the arguments he presents against other theories of evidence applied to law-e.g., the conjunction problem, the reference class problem, the objection against a probabilistic appraisal of evidence based on the computational intractability of updating prior probabilities, the mental experiment designed to show how base rates and assignments of probabilities must be related in order for a standard of proof to minimize expected loss ${ }^{14}$ —or supporting his own view_e.g., the argument for the reciprocity of the burdens of persuasion ${ }^{15}$, the distinction between narratives and explanations ${ }^{16}$, the metaphor of legal systems as evolutionary optimization problems and neural networks ${ }^{17}$ - are not only genuinely conceptual, but also unlikely to be brought back to supervenience relations on (or reduction relations to) a unique set of precisely identifiable natural properties. On the other hand, without the support of precise laws of supervenience (or of concept- and theory-reduction), sheer reference to empirical or scientific evidence in the context of the explanation of a social practice, even if useful, is not sufficient to qualify a theory as naturalistic or empirical, in the sense of naturalized epistemology (and jurisprudence). This comment, however, needs a clarification.

If we strip away from RCT the methodological requirement of equipping a naturalized epistemology with an explanation of the principles governing the relation of evidential support or justification between a set of empirical propositions and a conceptual claim, RCT itself reduces to a generic prohibition to disinterest in scientific or empirical facts about human behavior/psychology/biology, and nature in general. The latter, however, is a simple expression of good common sense. Its rejection would

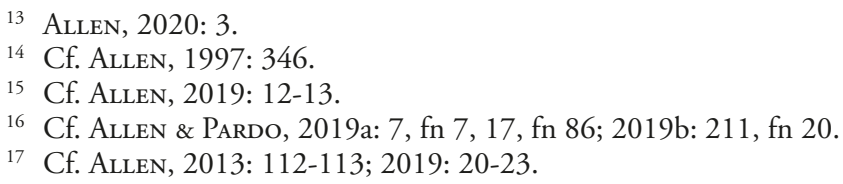


amount to a very peculiar philosophical move, a move that surely cannot be sensibly made when trying to elucidate the concepts that articulate our understanding of a social practice (e.g., the legal practice of civil trials in a U.S.A. jurisdiction) ${ }^{18}$. Otherwise, how could they be analyzed as articulating a certain practice in the first place? If concepts depend on social linguistic and inferential practices, then the facts about these practices - about what we do when we talk and engage in reasoning — cannot be irrelevant to non-formalist conceptual analysis. What I'm saying is that weakening RCT results in an epistemological technique which can be hardly distinguished from a quite common and traditional variety of conceptual analysis: conceptual clarification ${ }^{19}$.

Still, according to this conception of philosophy, empirical evidence does not affect concept-use and conceptual relations in a simple, straightforward way. More specifically, conceptual claims are neither justified nor supported by empirical evidence alone. A defender of conceptual clarification might contend that we learn our concepts through conditioning, training, and enculturation, not by sheer induction or abduction from our past and present experiences, and that, analogously, even if we often modify our concepts under the impact of empirical discoveries, this does not imply that the new concepts are induced or abduced from the latter: rather, the practice-e.g., the way we identify things-effects that a certain empirical evidence $\mathrm{E}$ is treated as a new criterion for the application of the concept $\mathrm{C}$, thereby establishing a new conceptual relation between $\mathrm{E}$ and $\mathrm{C}$.

In other words, some empirical propositions are treated as rules of concept-use and thus become relevant for the meaning of certain interactions, not as evidence for testable generalizations or hypotheses about individual or social human biology. This is the reason why Ludwig Wittgenstein portrayed conceptual analysis as a therapeutic clarification based on perspicuous descriptions of language- and concept-use rather than as a theoretical explanation of causal relations between sensorial inputs and linguistic outputs. A consequence of this approach is the rejection of the simplistic conclusion that "philosophical claims are always vulnerable to the success of a posteriori inquiry» ${ }^{20}$ : empirical discoveries cannot refute philosophical claims, because the latter are not propositions, but representation-rules whose function is to show conceptual relations. A philosophical claim can only be «refuted» showing that it is incompatible with other already "accepted» philosophical claims.

Secondly, the fact that naturalized normative epistemology forbids any ultimate appeal to intuitions is not a differentiating trait of this conception, since concep-

18 This means that the theories criticized by ALLEN are not only empirically, but also conceptually inadequate.

19 However, it is also strikingly similar to other kinds of conceptual analysis: compare, for example, Allen's RPT and Jules Coleman's pragmatic conceptual analysis of tort law (as exposed in ColEmAN, 2001).

20 Cf. Allen \& Leiter, 2001: 1495. 
tual clarification can easily comply with it. As Constantine Sandis aptly noticed, those who believe the contrary (e.g., experimental philosophers, Leiter, but also defenders of conceptual analysis, as Kenneth E. Himma ${ }^{21}$ ) mistakenly identify "claims about how "one" (or "we") would ordinarily apply a word [or use a concept, for the case] with beliefs or intuitions about correct usage» ${ }^{22}$. Conceptual clarification need and does not rely on intuitions: it focuses on the rules implicit in the linguistic and non-linguistic behaviors of the participants to a social practice in order to describe its conceptual articulation, using as analytic tools logic(s), philosophical distinctions, appropriately contextualized mental experiments. Besides, those who defend this way of philosophizing have their arguments against the equation of competence (and correct use) with majoritarian use or natural dispositions ${ }^{23}$.

Third, «the two constraints of naturalized [normative] epistemology: "ought implies can" and the instrumental character of normative advice» ${ }^{24}$ are simply not characteristic of naturalized epistemology alone. Many defenders of traditional (normative) epistemology would profess adherence to such principles-even if in some limited cases their application may be controversial.

In sum, Allen's meta-epistemology is surely incompatible with some kind of a priori, «immodest», «formal» conceptual analysis, but this is not sufficient to qualify as «naturalized» his epistemology, since it is not clearly distinguishable from a traditional way of practicing conceptual clarification. In fact, he often defends his theses resorting to conceptual arguments, and there are reasons to doubt that RPT mainly rests on empirical grounds, as I'll try to show in the following section.

\section{THE EMPIRICAL CHARACTER OF THE RELATIVE PLAUSIBILITY THEORY}

2.1. Let us now turn to the meaning of «empirical». In a paper coauthored with Michael Pardo, Allen claims that the task of their research project «is empirical: what is the best explanation of the data, where "the data" are observations of how the American legal system structures proof at trial?» ${ }^{25}$. However, in what sense is it empirical an explanation of data, consisting in observations of the ways a specific legal system structures proof at trial? Italics signal the need for a clarification of these notions, because they are controversial and equivocal.

\footnotetext{
21 Cf. Leiter, 2003: 43-44; Himma, 2015: 74-75, 77. See also Allen \& Leiter, 2003: 892.

22 Cf. SANDis, 2010: 183.

23 Cf. Medina, 2002: ch. 4 and 5; 2006: 35.

24 Cf. Allen \& Leiter, 2001: 1503.

25 Allen \& Pardo, 2019a: 7.
} 
According to the authors, RPT seeks to offer the best empirical account of juridical proof and the entire litigation process in American legal systems, seen as a complex, organic, dynamic, and adaptive system ${ }^{26}$. As they precise,

$[\mathrm{RPT}]$ is about the entire process of proof, including (1) the form, securing, and presentation of evidence, (2) the forms of argumentation employed at trial, (3) the manner in which humans process and deliberate on evidence, (4) the trial structure created by the rules of evidence and procedure, (5) the structure of litigation before and after trial, (6) the manner in which judges and juries, on the one hand, and trial and appellate judges, on the other hand, interact, and (7) to some extent about the meaning and nature of rationality ${ }^{27}$.

It seems then that Allen and Pardo aim at explaining empirically each one of the seven objectives enumerated and their mutual connections. This ambition, and the efforts devoted to realize it, are praiseworthy. However, the declared objectives are very heterogeneous and ask for different methods of inquiry, some of which can be doubted as to their empirical (or scientific) character. I'm referring, especially, to the explanation of (4): its object is a normative legal order, a social practice in which standards, rules, and principles play a central role. In this case, the doubts do not stem from the idea that norms are not empirical objects—an idea Allen is committed to reject, given his naturalism. The problems are rather methodological.

Let us assume that empirical social sciences can describe-among other thingsthe beliefs, value-judgments, rules/methods, and choices of the members of a community engaged in a social practice. Since all these aspects are expressed through their discourses, the discourses of the social sciences are (at least in a loose sense) meta-linguistic. Now, a first methodological problem for the social scientist (or the historian) is that the recognition and description, in the meta-language of the social science, of a complex linguistic normative structure (e.g., an ideology, a philosophical current, a legal order), and even its reduction to specific representative sentences, are only possible through the difficult selection and application of a set of conceptual criteria - that is, norms - of identification. A second methodological problem depends on the fact that all social practices distinguish a correct way of participation and engagement from more or less serious errors: an adequate description of the practice must then take into account this normative component (even if the theorist ends up re-describing it as a collective illusion, ideology, or cognitive dissonance). A third methodological problem concerns the empirical adequacy of the theories which ascribe meanings to social behaviors.

The choice of the criteria of identification is guided by the purpose of giving the best explanation of the practice, reproducing the beliefs, values, methods, and choices of the subjects whose practices we wish to describe. However, this preliminary methodological operation is extremely delicate: since the application of the selected criteria implies a simplification, an idealization, and the imposition of a descriptive

26 Cf. ibidem; Allen, 2020: 3.

27 Allen \& Pardo, 2019b: 207-208. 
model to the practice, the risk of projecting the theorist's views onto the practice to be described lurks constantly in the background. It is thus essential to distinguish the normative criteria functional to the description of social values, beliefs, methods, and choices of the practitioners from the values, beliefs, methods, and choices the theorist considers rational and justifiable. In the case of legal analysis, it is important to specify if the attitudes and methods expressed in the discourses of the legal operators are identified by looking at the actual discourses the majority of each subgroup of practitioners produces, or at the discourses they say they are producing, or wanting to produce, or at the «best examples» of such discourses according to the observer.

Social theorists and historians are accustomed to such problems and try to avoid them making explicit their criteria of identification, varying such criteria in order to confront the resulting explanations, including in the description the attitudes and (linguistic or non-linguistic) actions they consider irrational/unjustified, but endowed with a relevant social diffusion, and accounting for the distance between the explicit (self-)definitions or (self-)representations of the practitioners and their real behavior. The officials of a legal order, on the other hand, do not care about all these descriptive facets (and do not praise explanations that preserve the "pluralism» of the practice) when they try to set what the law is or «says» on a specific matter. Neither do formal legal doctrine and descriptive jurisprudence/legal theory, even if they work on a different level of systematic and generality. This happens because, while operating with a (not too precise) common sense concept of law/legality, they are concerned with deriving from the law itself-not from the concept of law-the (more precise) technical criteria for its description-rectius: for the recognition of its sources and the determination of its normative contents-in order to find out the legal solution to a practical problem. Officials and formal legal doctrine assume law's criteria of self-delimitation as given: an assumption an empirical social scientist cannot accept, but must substitute with a testable theory about the effectiveness of the preferred rule of recognition.

What about RPT? As shown by the array of examples in the footnotes of the target paper, Allen is a profound connoisseur of statutory and common law of evidence in the U.S.A. Nonetheless, his theory does not follow the methods of empirical social sciences for the identification of their explanatory units. Nor does it proceed-at least to my knowledge-from a systematic and detailed recollection of sufficiently wide and statistically representative samples of procedural documents, proffered evidence, reported judicial decisions, verdicts of the juries, interviews to professional and lay legal operators, etc ${ }^{28}$. In this sense, Allen is neither developing nor relying on a sociological theory of evidence law to support his claims about American legal systems. On the other hand, if the "observations» of the ways a specific legal order structures proof at trial consist in the "best»—-more comprehensive, coherent, sim-

28 Allen shows an acute perception of many concrete aspects of the litigation practice, but does not provide an explicit systematic empirical support to the explanations of (1), (2), (5), (6) either. 
ple, efficient, etc...-literal, systematic and teleological interpretations of statutes, precedents, jury instructions et similia, the scrutiny of legal doctrines and the analysis of the concepts they incorporate, then it seems that RPT's explanation of (4) assumes the legal practice's self-identification criteria: it is elaborated from the internal point of view, not from the external point of view of empirical social sciences ${ }^{29}$. The practice, however, could well be more or less incoherent, or insensible to some features of legal rules, formal legal doctrines and best jurisprudential reconstructions (such as RPT): a possibility Allen does not explore empirically.

2.2. Where does then lie the empirical base of RPT? Almost entirely in the explanation of (3), which recruits the "story model» resulting from the researches in social and cognitive psychology conducted by Nancy Pennington and Reid Hastie. Still, even leaving aside concerns about the external and ecological validity of simulated trials, such a base does not suffice, in the light of the ambitious objectives of RPT, as an empirical theory. Here is a brief summary of some objections.

Daniel Simon argued that the story model «is of limited use in cases where there is not much of a story to tell, such as when the evidence is fragmented [...]. The same would apply to cases that hinge on technical judgments of patents, trademarks and antitrust, discerning causes of physical events, setting damage awards and so forth» ${ }^{30}$; again, "A narrative $[\ldots]$ is of little relevance to negligence cases where the contested issue is a failure in appreciating a risk, to identification cases, or to cases in which the material facts concern the physical conduct of the defendant, the quality of a product, the extent of the damages, and the like» ${ }^{31}$. Allen might reply that explanations in a trial context are not stories, and that holistic reasoning supplies the lacking part in RPT: but in that case he should go into details and make explicit testable hypotheses about the holism he endorses. Besides, RPT neglects the experimental evidence and scholarship on biases and external factors interfering with jury's decisions that exclude or impair plausibility assessments ${ }^{32}$.

However, let us grant, arguendo, that Allen has sufficient empirical support for the claim that fact-finders process - or even cannot but process - evidence at trial in a holistic way, comparing alternative explanations and assessing their relative plausibility. Does this claim in turn support the conclusion that American legal systemsstatutory rules, precedents, jury instructions, doctrines-are best explained by RPT? No, since the two are quite independent: much empirical (and conceptual) work is needed to link the explanation of (3) to an empirically well corroborated explanation of (4). And even if such a link were to be provided, there are good reasons to suppose that RPT would still need a conceptual framework whose elucidation cannot

29 Moreover, one may object that some aspects of the formal legal doctrine seem inconsistent with RPT (cf. SCHAUER, 2019: 182).

30 Simon, 2019: 84 .

31 Simon, 2004: 564

32 Cf. SротTswood, 2014. 
be reduced to theoretical posits or empirical evidence for (3), (4), etc., as I tried to highlight in $\$ 1.2$.

Finally, let us consider a different critical issue. In a rejoinder to some critics ${ }^{33}$, who lamented a lack of precision in the definition of the object of RPT and its analytic tools, and concern about empirical literature, Allen and Pardo defended their view arguing that a narrower focus on empirical legal scholarship would have "limited utility in furthering the understanding of an entity such as juridical proof» at the level at which they want to explain it. In this regard, they invoke the cognitive complexity of the reasoning of the different legal actors in particular contexts and the factual complexity of the huge amount of cases the legal systems deal with to express the «doubt that there will be a well-organized science (or philosophical thought) of how people decide one explanation is better than another, even though that is precisely what people do in a virtually infinite number of ways» ${ }^{34}$.

I think this reply misses the point of the criticism, which does not ask RPT to find a generalization or covering law in order to account or predict the decisions of individual cases. The objection, instead, is that an empirical explanation of the nature of legal proof should pay more attention to the results of empirical social sciences, as RCT prescribes. Consider human behavioral biology: its central object, human behavior, is extraordinarily complex, and can be approached scientifically from many different specific points of view (socio-biology, ethology, genetics, endocrinology, neurology, etc.). It is possible to elaborate a «big picture» of human behavior only transcending the boundaries of each discipline and reconstructing the complex connections between the phenomena studied by each one of them at different levels. Just like Allen tries to do with legal proof. But for RPT to became an empirical big picture, each explanation composing it should be empirically informed, as are the theories that illuminate different aspects of human behavior.

\section{REFERENCES}

Allen, R.J., 1986: «A Reconceptualization of Civil Trials», in Boston University Law Review, 66(3): 401-437.

—, 1997: «Reasoning and its foundation: Some responses», in International Journal of Evidence and Proof, 1 (special issue): 343-347.

—, 2013: «Taming complexity: Rationality, the law of evidence and the nature of the legal system», in Law, Probability and Risk, 12: 99-113.

—, 2019: «Standards of Proof and the Limits of Legal Analysis», in Diritto \& Questioni Pubbliche, 19(2): 7-25.

Allen, R.J., Leiter, B., 2001: «Naturalized Epistemology and the Law of Evidence», in Virginia Law Review, 87(8): 1491-1550.

33 Cf. Schauer, 2019; Simon, 2019; VÁzquez, 2019.

34 Allen \& Pardo, 20I9b: 210. 
—, 2003: «Naturalized Epistemology and the Law of Evidence: Reply to Redmayne», in The Michigan State Law Review, 2003(4): 885-892.

Allen, R.J., Pardo, M.S., 2019a: «Relative plausibility and its critics», in The International Journal of Evidence and Proof, 23(1-2): 5-59.

—, 2019b: "Clarifying relative plausibility: A rejoinder», in The International Journal of Evidence and Proof, 23(1-2): 205-217.

Coleman, J.L., 2001: The Practice of Principle, Oxford: Oxford University Press.

Hiмma, K.E., 2015: «Conceptual Jurisprudence. An Introduction to Conceptual Analysis and Methodology in Legal Theory», in Revus, 26: 65-92.

LeIteR, B., 1997: «Rethinking Legal Realism: Toward a Naturalized Jurisprudence», in Texas Law Review, 76(2): 267-315.

—, 2003: «Beyond the Hart/Dworkin Debate: The Methodology Problem in Jurisprudence», in The American Journal of Jurisprudence, 48(1): 17-51.

Medina, J., 2002: The Unity of Wittgenstein's Philosophy: Necessity, Intelligibility, and Normativity, Albany: State University of New York Press.

—, 2006: Speaking from Elsewhere, Albany: State University of New York Press.

Nixon, J., 2004: «What is theory?», in Educar, 34: 27-37.

SANDis, C., 2010: «The Experimental Turn and Ordinary Language», in Essays in Philosophy, 11(2): 181-196.

Schauer, F., 2019: «One small step towards a metatheory of evidence and proof», in The International Journal of Evidence and Proof, 23(1-2): 176-183.

Simon, D., 2004: «A Third View of the Black Box: Cognitive Coherence in Legal Decision Making», in The University of Chicago Law Review, 71(2): 511-587.

—, 2019: «Thin empirics», in The International Journal of Evidence and Proof, 23(1-2): 82-89.

SpotTswood, M., 2014: «Bridging the gap between Bayesian and story comparison models of juridical inference», in Law, Probability, and Risk, 13(1): 47-64.

VÁzquez, C., 2019: «Less probabilism and more about explanationism», in The International Journal of Evidence and Proof, 23(1-2): 68-74. 